\title{
Olive Leaves as Biotemplates for Enhanced Solar-Light Harvesting by a Titania-Based Solid
}

\author{
Jesús Hidalgo-Carrillo *(D), Juan Martín-Gómez $\mathbb{D}^{D}$, M. Carmen Herrera-Beurnio, Rafael C. Estévez, \\ Francisco J. Urbano* ${ }^{\mathbb{D}}$ and Alberto Marinas $\mathbb{D}$
}

Departamento de Química Orgánica, Instituto Universitario de Investigación en Química Fina y Nanoquímica (IUNAN), Universidad de Córdoba, Campus de Rabanales, Edificio Marie Curie, E-14071 Córdoba, Spain; juanmartingomez@outlook.es (J.M.-G.); b52hebem@uco.es (M.C.H.-B.); q72estor@uco.es (R.C.E.); alberto.marinas@uco.es (A.M.)

* Correspondence: yimo@hotmail.com (J.H.-C.); fj.urbano@uco.es (F.J.U.); Tel.: +34-957-218-638 (F.J.U.)

Received: 14 May 2020; Accepted: 26 May 2020; Published: 30 May 2020

\begin{abstract}
Olive leaves (by-product from olive oil production in olive mills) were used as biotemplates to synthesize a titania-based artificial olive leaf (AOL). Scanning electron microscopy (SEM) images of AOL showed the successful replication of trichomes and internal structure channels present in olive leaves. The BET surface area of AOL was $52 \mathrm{~m}^{2} \cdot \mathrm{g}^{-1}$. X-ray diffraction (XRD) and Raman spectra revealed that the resulting solid was in the predominantly-anatase crystalline form ( $7.5 \mathrm{~nm}$ average particle size). Moreover, the synthesis led to a red-shift in light absorption as compared to reference anatase (gap energies of 2.98 and $3.2 \mathrm{eV}$, respectively). The presence of surface defects (as evidenced by $\mathrm{X}$-ray photoelectron spectroscopy, XPS, and electron paramagnetic resonance spectroscopy, EPR) and doping elements (e.g., $1 \%$ nitrogen, observed by elemental analysis and XPS) could account for that. AOL was preliminarily tested as a catalyst for hydrogen production through glycerol photoreforming and exhibited an activity $64 \%$ higher than reference material Evonik P25 under solar irradiation and $144 \%$ greater under ultraviolet radiation (UV).
\end{abstract}

Keywords: olive leaf; biotemplating; titania-based materials; textural and structural characterization; solar-light harvesting; photocatalysis; hydrogen production

\section{Introduction}

Bio-inspired materials are a promising research area for the development of advanced systems with higher environmental compatibility, recyclability and energetic efficiency [1]. Some of the advantageous properties of natural materials include sophistication, miniaturization, hierarchical organization, resistance and adaptability, which are the result of billions of years of evolution [2]. The morphologies of biological structures ranging from nanometers to the millimeter scale can inspire the design of artificial materials to be used for energy capture, storage and conversion [3-5].

The use of natural materials as biotemplates to obtain heterogeneous catalysts is effective in overcoming the difficulty of controlling the morphology of the final solid [6-8]. The main advantage of this approach is that the final structure can be easily designed by the selection of a template with a specific morphology, while conventional synthesis processes, such as the sol-gel method, are greatly affected by the synthetic conditions, such as the $\mathrm{pH}$ of the solution, the drying process, subsequent heat treatments, etc.

Hydrogen is considered to be an efficient source of non-polluting energy, with an acceptable cost in the medium and long term. Currently, hydrogen is mainly produced by steam reforming and water electrolysis [9]. The former approach has the disadvantage of using non-renewable fossil sources and, therefore, the co-generated $\mathrm{CO}_{2}$ directly impacts the environment through the greenhouse effect. 
A second drawback of steam reforming is its high operating temperature. As for hydrogen production through water electrolysis, its main associated problem is the high consumption of electrical energy [9]. Alternatively, solar thermal energy can be used but then large and expensive facilities are required.

In addition to the above-mentioned technologies for hydrogen production, some innovative techniques are being developed that could be complementary to those already existing in the medium-term future. Among them, photocatalytic reforming of oxygenated organic compounds is one of the most promising. It consists in the treatment of such compounds with light radiation in the presence of water, at room temperature and anaerobic conditions, to generate gaseous hydrogen and carbon dioxide [10]. The process is particularly interesting from the environmental point of view if biomass residues or by-products (bio-glycerol or glucose, among others) are used as oxygenates since, in this case, the $\mathrm{CO}_{2}$ generated is consumed by the biomass itself during its growth, so the carbon cycle is closed. One of the key points to the success of this technology is the development of some suitable catalysts (i.e., semiconductors) able to maximize the light harvesting and therefore the hydrogen production [11]. Titania is the most widely used semiconductor due to its excellent stability during the photochemical process. However, it has several drawbacks, such as an Eg $>3.0 \mathrm{eV}$, which limits its capacity to absorb visible radiation and a high electron hole recombination rate. In recent years, some intense research has been developed aimed at improving the photocatalyst in this type of process. There are two main ways to retard the electron-hole recombination in $\mathrm{TiO}_{2}$ : (i) the generation of irregularities or surface defects, or (ii) the modification of $\mathrm{TiO}_{2}$ with a metal, creating a Shottky barrier in the junction zone between the two materials that would limit the recombination process, by flowing electrons generated from the valence band of $\mathrm{TiO}_{2}$ to the metal [12]. Noble metals such as Pt, $\mathrm{Pd}$ or $\mathrm{Au}[10,13]$ have been found to be particularly effective though there is a need to use some more cost-effective transition metals such as Fe, $\mathrm{Cu}$ or $\mathrm{Ni}$ [14-16]. This barrier can also be created by modifying $\mathrm{TiO}_{2}$ with carbon nanostructures, such as nanotubes or graphene [17]. Another strategy is to couple $\mathrm{TiO}_{2}$ with a semiconductor having a smaller band gap to form a heterostructure. This way, heterojunction promote the separation of photoexcited electron hole pairs through several carrier-transfer pathways by keeping reduction and oxidation reactions at two different reaction sites. Moreover, the coupled semiconductors can extend the light response range to the visible [18].

Recent studies on the use of bio-templates for the synthesis of titania-based catalysts have led to solids operating in the visible range [19,20]. Therefore, for instance, Mohamed et al. [21] developed mesoporous nanotubes of $\mathrm{TiO}_{2}$ replicating the cellulose structure, thus obtaining a catalyst with high catalytic efficiency in removal of organic pollutants from wastewater when illuminated with visible light. In a different approach, Hashemizadeh et al. [22] described a procedure whereby Camellia leaves were modified through incorporation of $\mathrm{TiO}_{2}$ and subsequently of $\mathrm{RuO}_{2}$. The use of the plant's light collection system (mesoporous structures imitating the pores in green leaves) allowed the resulting solid to exhibit better results in $\mathrm{CO}_{2}$ reduction or ethanol reforming than Evonik P25 itself (a reference titania photocatalyst), the artificial $\mathrm{TiO}_{2}$-based leaves even operating under visible light. These studies are a source of inspiration for some other approaches aimed at valorizing different regional biomass by-products which could contribute to the economic development of involved regions.

The European Union (EU) is the leading world producer of olive oil (roughly $80 \%$ of the total output with 37\% of the global figure coming from Andalusia, where ca. 250,000 families live on olive cultivation). One of the by-products obtained in the oil mills is the olive leaf. During the previous process of cleaning the olive, a considerable amount of olive leaves is separated representing ca. $8 \%$ by weight of the milled olive. Those leaves can be used for livestock feed (although its use is limited by the bad taste that confers the olive juice), as a fuel in power generation plants [23] and as biomass source for obtaining nutraceuticals [24] or potential drugs [25].

In the present piece of research, the structure of natural olive leaves has been replicated for the synthesis of new $\mathrm{TiO}_{2}$ structures capable of capturing visible light. Furthermore, as a proof of concept, some preliminary results on hydrogen production through glycerol (bioproduct from biodiesel obtaining) photoreforming are presented. 
By this way, a titania-based biomimetic material (artificial olive leaf, AOL) has been synthesized with enhanced optical properties (i.e., light absorption extended to visible) and with a larger amount of interstitial defects than reference Evonik P25. Thus, the electron-hole recombination rate would be reduced and photo-catalytic performance enhanced, as proved in the aqueous glycerol photoreforming leading to hydrogen generation.

\section{Materials and Methods}

\subsection{Synthesis of Artificial Olive Leave (AOL)}

The replication of architectures of olive leaf was done according to the method described by Li et al. [19] slightly modified. Figure 1 includes several pictures taken at the different steps of the synthetic method. In short, $10 \mathrm{~g}$ of fresh olive leaves were cut and washed with Milli-Q water and subsequently treated, under inert $\left(\mathrm{N}_{2}\right)$ atmosphere, with a $0.5 \%(\mathrm{v} / \mathrm{v})$ solution of $\mathrm{HCl}$ until the leaf coloration changed from green to brown. Then, $30 \mathrm{~mL}$ of $15 \% \mathrm{TiCl}_{3}$ water solution (Sigma-Aldrich, Darmstadt, Germany) was added to carry out the ionic exchange and left under vigorous stirring overnight. The leaves were then filtered and washed with Milli-Q water 3 times and left to dry in a vacuum desiccator. The dry leaves were suspended in $100 \mathrm{~mL}$ of isopropanol (Merck, Hunterdon County, NJ, USA) for $12 \mathrm{~h}$ under stirring, to remove traces of water. They were subsequently filtered and suspended again in $100 \mathrm{~mL}$ of isopropanol, $9 \mathrm{~mL}$ of titanium isopropoxide (Sigma-Aldrich, Darmstadt, Germany) were added and the suspension was left stirring overnight. Finally, the suspension was refluxed at $80{ }^{\circ} \mathrm{C}$ for $6 \mathrm{~h}$, the solid was filtered, dried at $120^{\circ} \mathrm{C}$ and calcined at $550{ }^{\circ} \mathrm{C}$ for $6 \mathrm{~h}$ thus obtaining the AOL (standing for Artificial Olive Leaves). In addition to AOL, two commercial titania materials were used for comparative purposes: Anatase (Sigma-Aldrich, Darmstadt, Germany) and Aeroxide ${ }^{\circledR}$ P25 (Evonik, Essen, Germany).
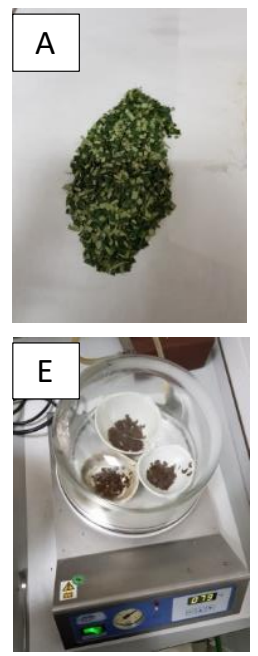
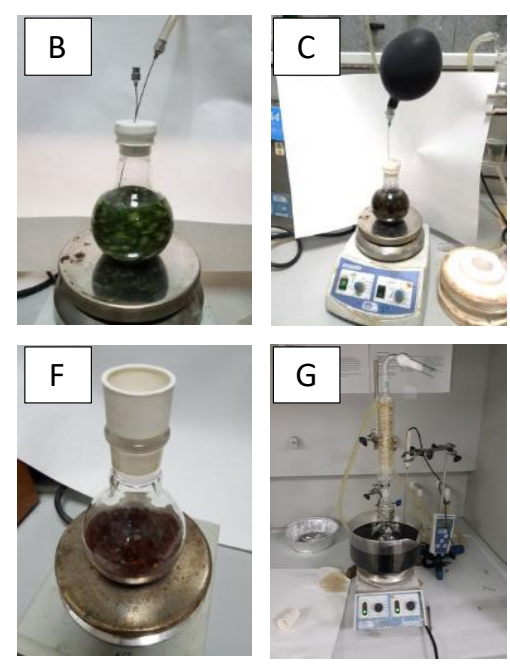
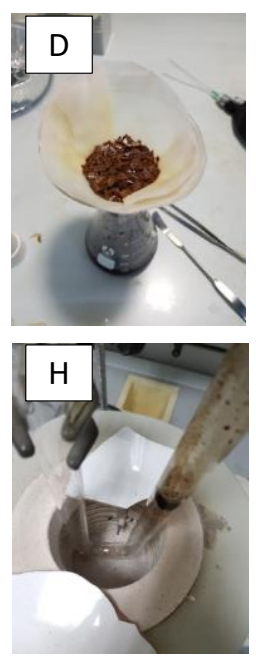

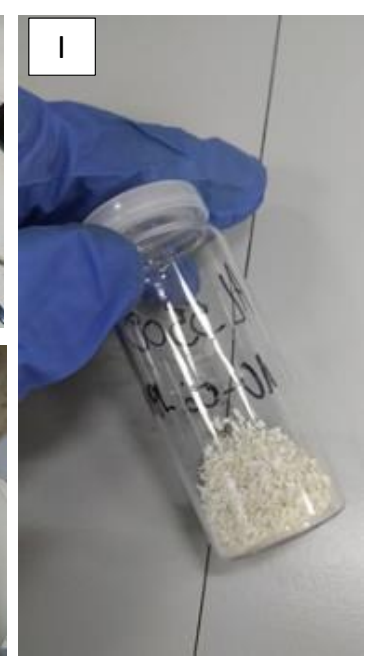

Figure 1. Pictures taken at different steps during the synthesis of AOL. (A) Fresh olive leaves cut and washed. (B) Acid hydrolysis under $\mathrm{N}_{2}$ atmosphere. (C) Addition of $\mathrm{TiCl}_{3}$ under $\mathrm{N}_{2}$ atmosphere. (D) Filtering and washing. (E) Drying at $120^{\circ} \mathrm{C}$. (F) Suspension of leaves in isopropanol and titanium isopropoxide. (G) Reflux at $80^{\circ} \mathrm{C}, 6 \mathrm{~h}$. (H) Calcination at $550{ }^{\circ} \mathrm{C}$. (I) Resulting AOL.

\subsection{Characterization of Artificial Olive Leave (AOL)}

X-ray fluorescence analyses was carried out on a Rigaku tube-above wave-length dispersive X-ray fluorescence ZSX Primus IV spectrometer (Rigaku, Austin, TX, USA), equipped with an X-ray tube with $4 \mathrm{~kW}$ rhodium anode, a proportional gas flow detector for light elements and a scintillation counter for heavy elements. 
The elemental analysis for the AOL solid was carried out at the Central Service for Research Support (SCAI) of the University of Córdoba, using a Eurovector EA-3010 elemental analyzer (Eurovector, Pavia, Italy).

Scanning electron microscopy (SEM) and energy-dispersive spectroscopy (EDS) analysis were obtained at the Central Service for Research Support (SCAI) of the University of Córdoba with a JEOL JSM 7800F microscope interfaced to an Oxford Instruments X-max 150 semi-quantitative elemental microanalyzer (Jeol, Tokyo, Japan).

Nitrogen adsorption-desorption isotherm, at the liquid nitrogen temperature, were performed on an Autosorb-iQ-MP/MP-XR device (Anton Paar, Graz, Austria), using the Brunauer-Emmet-Teller (BET) method for the calculation of the surface area, the BJH method for the calculation of the area and the volume of mesopores and macropores and the $V$ - $t$ method for the calculation of the area and pore volume of micropores. Before measurements, all samples were degassed at $120^{\circ} \mathrm{C}$ and $0.1 \mathrm{~Pa}$.

XRD analysis were performed on a Bruker D8 Discover (Bruker Española S.A., Madrid, Spain) with a monochromatic $\mathrm{CuK} \alpha 1$ radiation $\left(\lambda=1.54 \AA\right.$ ) over an angular range of $10-80^{\circ}$ at a scan speed of $1.45^{\circ} 2 \theta \cdot \mathrm{min}^{-1}$.

Raman spectroscopy was carried out at the Central Service for Research Support (SCAI) of the University of Córdoba on a confocal NRS-5500 Raman spectrometer (Jasco Inc., Tokyo, Japan) with $532 \mathrm{~nm}$ laser excitation, L1800 grating and an EMCCD detector. Spectra were taken through 20x objective lens, accumulating 10 scans (10 s exposure) with a laser power at sample point of $0.7 \mathrm{~mW}$.

Diffuse reflectance UV-Vis spectra were performed on a Cary 1E (Agilent, Santa Clara, CA, USA) instrument, using polytetraethylene as reference material. Band gap (Eg) values were obtained from the plot of the modified Kubelka-Munk function $[F(R) \cdot E]^{1 / 2}$ versus the energy of the absorbed light E.

X-ray photoelectron spectroscopy (XPS) data was recorded at the Central Service for Research Support (SCAI) of the University of Córdoba on pellets after outgassing the samples to a pressure below $2 \times 10^{-8}$ Torr at $150^{\circ} \mathrm{C}$. A Leibold-Heraeus LHS10 spectrometer (SPECS, Berlin, Germany) was operated with the $\mathrm{AlK} \alpha(h v=1486.6 \mathrm{eV}) \mathrm{X}$-ray source at $120 \mathrm{~W}$ and $30 \mathrm{~mA}$ using C $(1 \mathrm{~s})$ as energy reference $(284.6 \mathrm{eV})$.

Electron paramagnetic resonance (EPR) spectra were recorded on a Bruker EMX micro (Bruker, Española S.A, Madrid, Spain) applying and X-band $(9.43 \mathrm{GHz}, 1.5 \mathrm{~mW})$ microwave with sweeping magnetic field at $-173^{\circ} \mathrm{C}$.

\subsection{Photo-Catalytic Experiments}

The liquid-phase photocatalytic reactions were performed in two different devices using suspensions of $1 \mathrm{~g} \cdot \mathrm{L}^{-1}$ catalyst in $10 \%(\mathrm{v} / \mathrm{v})$ glycerol in water solutions under inert atmosphere.

For experiments under UV light, the device consisted in a Pyrex cylindrical doubled-walled immersion well reactor $(23 \mathrm{~cm} \times 5 \mathrm{~cm}$ internal diameter, with a total volume of $190 \mathrm{~mL})$ equipped with a gas circulation system (Ar, $5 \mathrm{~mL} \cdot \mathrm{min}^{-1}$ ), and a medium pressure $125 \mathrm{~W}$-Hg lamp (Photochemical Reactors Ltd., Reading, UK), used as the excitation source (Figure 2A). During the process, Ar was bubbled through the suspension $\left(20 \mathrm{~mL} \cdot \mathrm{min}^{-1}\right)$. Outlet gas composition was on-line analyzed by mass spectrometry.

For solar-light experiments, reactions were performed under nitrogen atmosphere in a $30 \mathrm{~mL}$ double mouthed heart-shaped reactor with light (from a Newport solar simulator furnished with a $150 \mathrm{~W}$ xenon lamp) focalized on the sample compartment through an optic fiber (Figure 2B). Analyses were performed by sampling with a pressure-lock precision analytical syringe (Valco VICI Precision Syringes, $1 \mathrm{~mL}$, leak-tight to $250 \mathrm{psi}$ ) from the head space of the photoreactor at selected times. Samples were analyzed by gas chromatography with a thermal conductivity detector (GC-TCD) on an Agilent Technologies 7890A gas chromatograph (Agilent, Santa Clara, CA, USA) furnished with a Supelco Carboxen ${ }^{\mathrm{TM}} 1010$ Plot column (Sigma-Aldrich, Darmstadt, Germany).

Lamps power at the sample compartments as measured at $<800 \mathrm{~nm}$ with an Ophir Starlite equipment were $116 \mathrm{~mW} \cdot \mathrm{cm}^{-2}$ and $106 \mathrm{~mW} \cdot \mathrm{cm}^{-2}$ for UV lamp and solar simulator, respectively. 


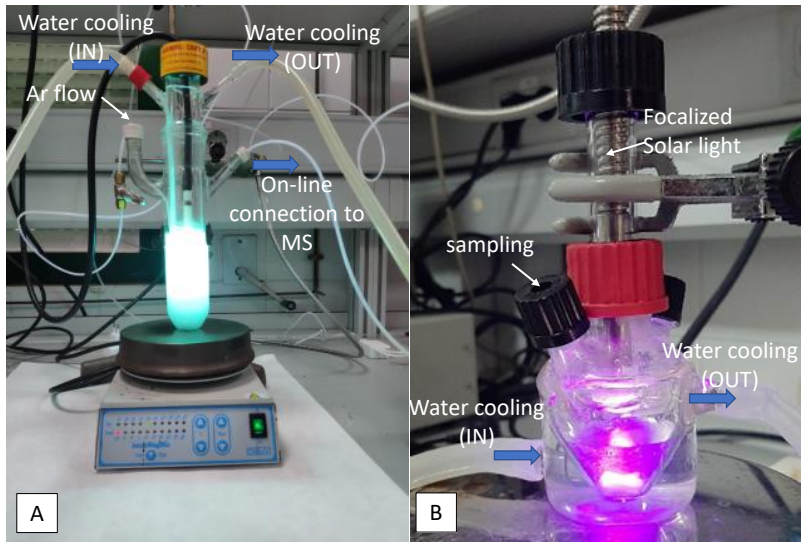

Figure 2. Picture of the photocatalytic reactors used in the hydrogen production from glycerol photo-reforming. (A) UV-light. (B) Solar light.

\section{Results and Discussion.}

\subsection{Olive Oil Leaf Structure}

Olive leaves (Olea europaea) are evergreen leaves with a 3-9 $\mathrm{cm}$ long and 1-2 cm wide limb, a very marked central nerve and a very short petiole (Figure 3A). The epidermis has a cuticle where the stomata are observed, much more abundant on the underside. The stoma is protected by scaly umbrella-shaped hair (trichomes, Figure 4A) whose function is to avoid the loss of water by evaporation. Underneath the epidermis the palisade parenchyma can be found consisting of three compact layers of cells superimposed on the beam and one layer on the underside. Inside the parenchyma cells of the olive leaves there are chloroplasts (Figure 3B), which are organelles in which photosynthesis is performed. Inside the chloroplasts there are thylakoids, flattened sacs delimited by a membrane and stacked forming structures called grana (granum), with a diameter between 0.3-0.6 $\mu \mathrm{m}$. These stacks are connected laterally to each other by membranes, forming a continuous compartment within the chloroplast. The chloroplast space surrounding the thylakoids is called stroma.

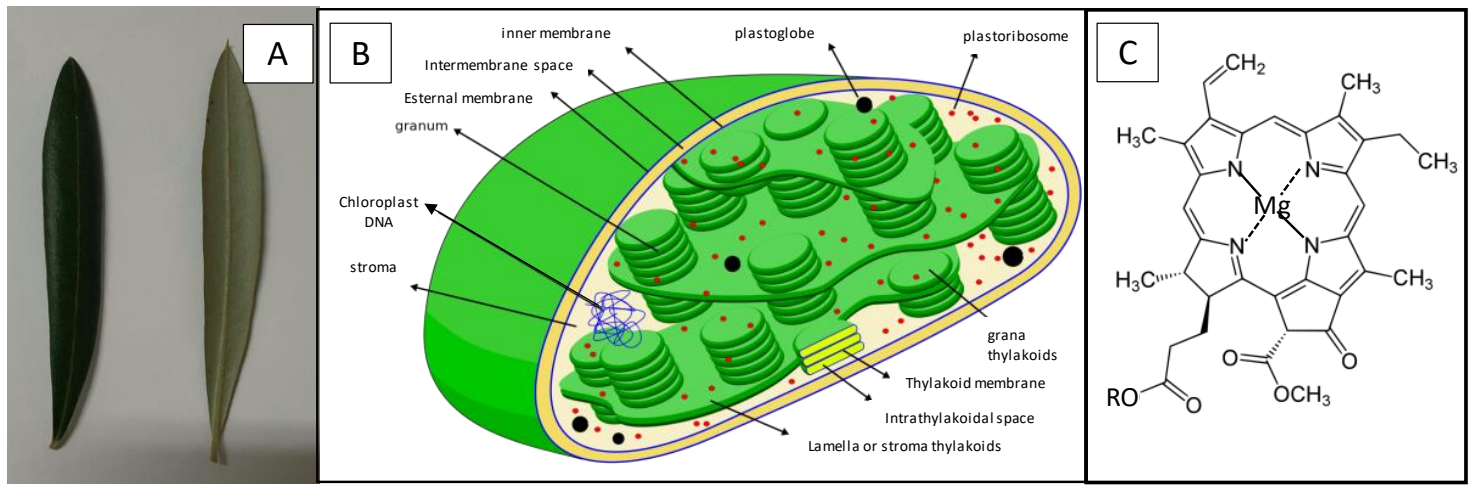

Figure 3. (A) Picture of olive leaves. (B) Structure of chloroplast, responsible for photosynthesis (Source: Miguelsierra/CC BY-SA (https://creativecommons.org/licenses/by-sa/4.0)). (C) Chlorophyll A structure where $\mathrm{R}$ denotes the phytol chain.

The main mission of chloroplasts is to develop photosynthesis, that is, the conversion of electromagnetic sunlight energy into chemical energy through chlorophyll molecules, adenosine triphosphate (ATP) synthase and ribulose biphosphate carboxylase/oxygenase. The thylakoid membrane contains the molecules responsible for performing the light phase of photosynthesis (photochemical phase), while in the stroma surrounding the thylakoids the dark (non-luminous) phase of photosynthesis takes place. 
Chlorophyll molecules (Figure 3C) are formed by a hydrophobic phytol chain and a magnesium containing porphyrin ring, which acts as a light collector during photosynthesis [26].

All in all, nature has developed complex systems for light harvesting over millions of years of evolution which are a source of inspiration when planning the design of efficient systems to capture light.
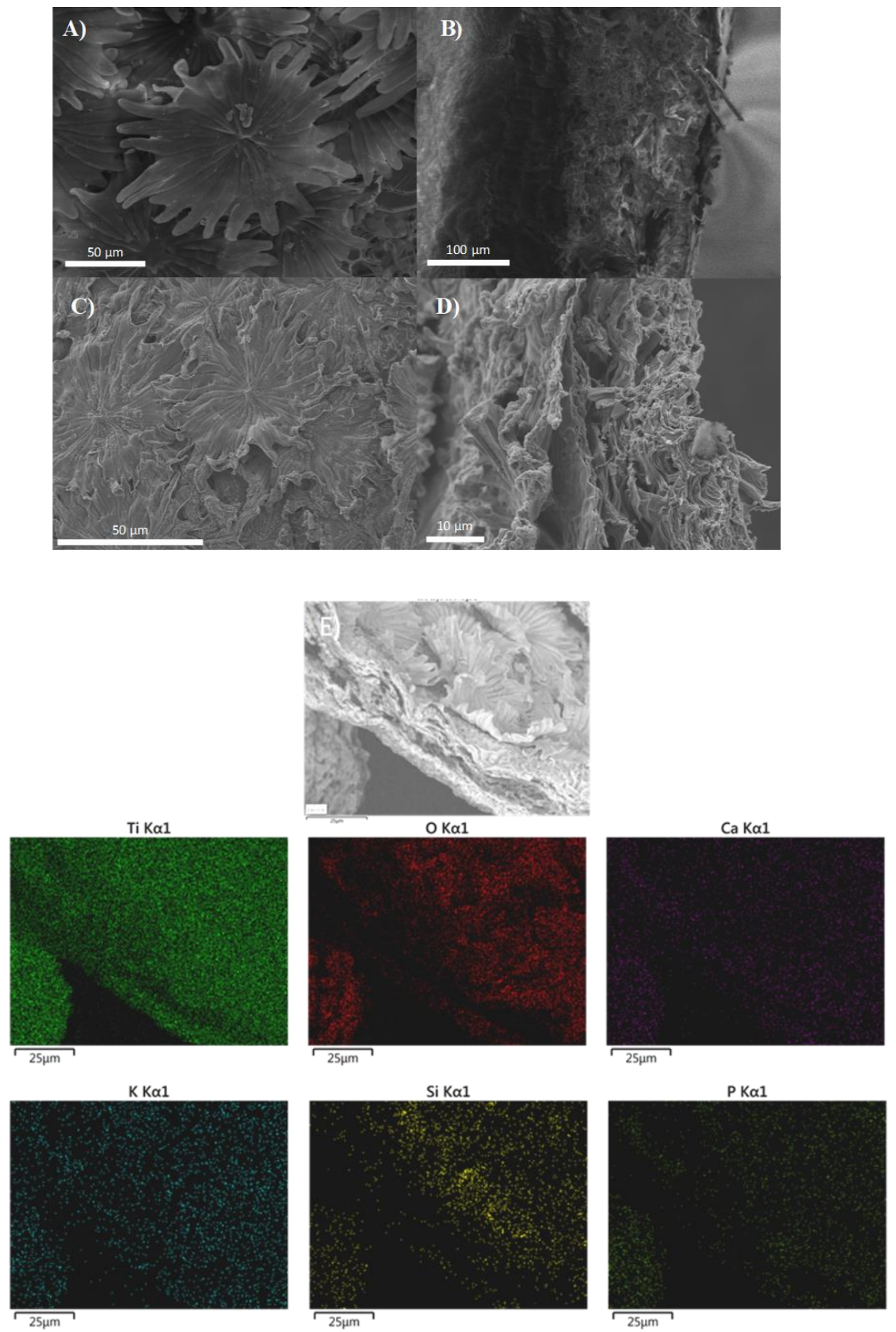

Figure 4. SEM images of a fresh olive leaf $(\mathbf{A}, \mathbf{B})$ and the artificial olive leaf $(\mathbf{C}, \mathbf{D})$. (E) Elemental mapping (SEM-EDX) of AOL sample indicating the distribution of Ti, O, Ca, K, Si and P.

\subsection{Synthesis of Artificial Olive Leaves (AOL)}

Artificial olive leaf (AOL) was synthesized by mimicking the structure of the olive leaf, following the procedure described by Li et al. [19] and subsequently modified by Hashemizadeh et al. [26]. The process basically consists of three phases, (i) an acid treatment by which several metal cations such 
as $\mathrm{Ca}, \mathrm{P}, \mathrm{S}, \mathrm{K}$ could be (partially) eliminated and, especially, $\mathrm{Mg}$ from the porphyrins, can be replaced by $\mathrm{H}^{+}$, forming yellow-brown pheophytins; (ii) a second step in which these protons are exchanged for $\mathrm{Ti}^{+3}$ through a treatment with $\mathrm{TiCl}_{3}$ and (iii) a third step in which these $\mathrm{Ti}^{+3}$ ions act as seeds for the subsequent formation of a $\mathrm{TiO}_{2}$ structure that replicates that of the olive leaf. To achieve the optimal acid treatment, several tests were carried out submitting the olive leaves to $\mathrm{HCl}$ solutions of different concentrations $(0.5 \%, 1 \%$ and $5 \%)$. The use of $1 \%$ and $5 \% \mathrm{HCl}$ resulted in total degradation of the olive leaf while with $0.5 \% \mathrm{HCl}$ the desired partial degradation of the leaf was achieved, obtaining the brown color indicative of magnesium-proton exchange in porphyrins.

\subsection{Chemical Analysis of $A O L$}

During biotemplating treatment, ca. $90 \%$ of the leaf weight was lost. Table 1 shows AOL elemental composition as determined by $\mathrm{X}$-ray fluorescence (XRF). For comparative purposes, composition of fresh olive leaves reported by Alcázar Román et al. [27] have also been included. As expected, titanium is the major element in AOL, accounting for $53.2 \%$ of weight (which expressed as $\mathrm{TiO}_{2} \%$ would represent ca. $89 \%$ of the catalyst weight). Other elements detected in AOL by XRF were calcium $(1.83 \%)$, phosphorus $(1.09 \%)$ and potassium $(0.95 \%)$. Those elements were already present in olive leaf. Complementary results using a CHN elemental analyzer, showed that AOL had a carbon content of $1.58 \%$ and a nitrogen content of $1.03 \%$. Thus, the $\mathrm{C} / \mathrm{N}$ weight ratio in $\mathrm{AOL}$ is much lower than that described in olive leaves [28] (1.5 and 33, respectively). This suggests that acid treatment and subsequent calcination of olive leaves led to the loss of most of carbon content whereas nitrogen present in the samples remained to a larger extent.

Table 1. Elemental composition of AOL as determined by XRF. For comparative purposes, composition of olive leaves [27] has also been included.

\begin{tabular}{ccc}
\hline Element & AOL (Weight \%) & Olive Leaf (Weight \%) \\
\hline $\mathrm{Ti}$ & 53.2 & - \\
$\mathrm{Ca}$ & 1.83 & 1.93 \\
$\mathrm{P}$ & 1.09 & 0.27 \\
$\mathrm{~K}$ & 0.95 & 0.90 \\
$\mathrm{~S}$ & 0.73 & 0.41 \\
$\mathrm{Si}$ & 0.38 & 0.12 \\
$\mathrm{Mg}$ & 0.12 & 0.21 \\
$\mathrm{Al}$ & 0.078 & 0.048 \\
$\mathrm{Fe}$ & 0.046 & 0.015 \\
$\mathrm{Zn}$ & 0.017 & 0.0023 \\
$\mathrm{Cl}$ & 0.0084 & 0.054 \\
$\mathrm{Sr}$ & 0.0077 & 0.0048 \\
\hline
\end{tabular}

\subsection{Morphology of the Synthesized AOL}

To evaluate the degree of emulation of the micro and/or nanostructure of the olive leaf in the synthesized material, AOL was analyzed by scanning electron microscopy (SEM). Figure 4 shows SEM images of a fresh olive leaf (A and B) and AOL (C and D). Figure $4 \mathrm{~A}$ is the underside of the olive leaf with the typical trichomes which were successfully replicated in AOL (Figure 4C).

Moreover, Figure 4B,D correspond to a cross-section of the olive leaf and the AOL catalyst, respectively. In these images, the internal structure corresponding to the parenchyma can be independently observed with the channels also replicated in the process. Dehydration and extraction of organic matter resulted in a contraction of the original microstructure of the olive leaf (compare Figure $4 \mathrm{~A}$ vs. Figures $4 \mathrm{C}$ and $4 \mathrm{~B}$ vs. Figure $4 \mathrm{D})$.

EDX analysis of AOL confirmed that it is mainly formed by titanium. Furthermore, some other minor elements were detected, such as $\mathrm{Ca}, \mathrm{P}, \mathrm{K}$ and $\mathrm{Si}$, in line with that found by XRF. Figure 4E includes 
a SEM-EDX elemental mapping of different elements present in AOL. As can be seen, titanium is homogeneously distributed in the sample.

\subsection{Textural Characterization of $A O L$}

$\mathrm{N}_{2}$ adsorption-desorption isotherm of AOL (Figure 5A) is type IV, associated to mesoporous materials. Surface area is $52 \mathrm{~m}^{2} \cdot \mathrm{g}^{-1}$, a similar value to that of reference material Evonik P25 $\left(51 \mathrm{~m}^{2} \cdot \mathrm{g}^{-1}\right)$ [29], whereas for anatase (Sigma-Aldrich, Darmstadt, Germany,) the surface area is ca. $45 \mathrm{~m}^{2} \cdot \mathrm{g}^{-1}$ [30]. BJH method showed that macroporous and mesoporous in AOL accounts for $46.36 \mathrm{~m}^{2} \cdot \mathrm{g}^{-1}$ (pore volume of $0.128 \mathrm{~cm}^{3} \cdot \mathrm{g}^{-1}$ ) whereas microporous have a surface area of $5.64 \mathrm{~m}^{2} \cdot \mathrm{g}^{-1}$ and a volume of $0.002 \mathrm{~cm}^{3} \cdot \mathrm{g}^{-1}$.
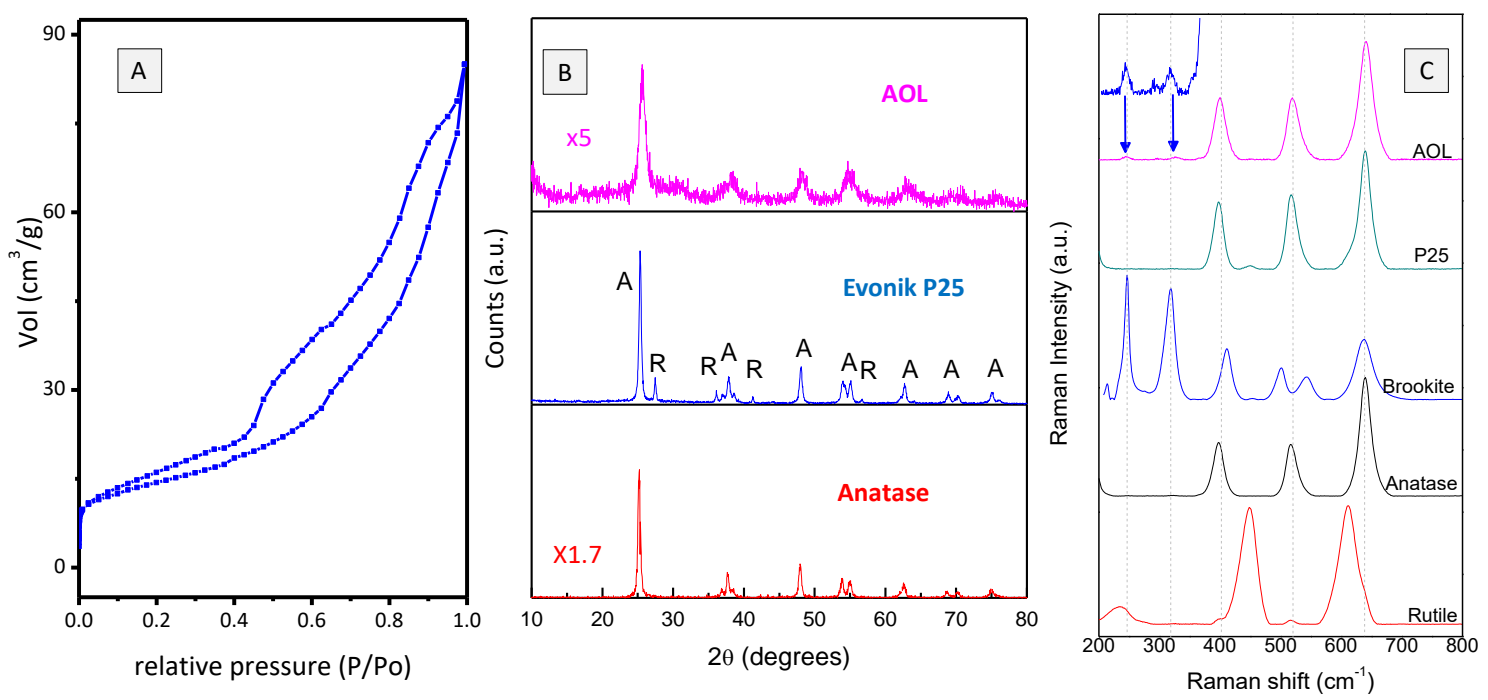

Figure 5. Characterization of AOL. (A) Nitrogen adsorption-desorption isotherm. (B) XRD pattern. Those patterns of Evonik P25 and Anatase have also been included for comparison. Anatase (A) and Rutile (R) peaks are marked for Evonik P25. (C) Raman spectra. For comparative purposes, spectra of brookite and rutile reference materials have also been included. Spectrum of brookite was obtained from RRUFF database (https://rruff.info/brookite/) whereas that of rutile corresponds to a reference material from Sigma-Aldrich (Sigma-Aldrich, Darmstadt, Germany).

\subsection{Structural Characterization of $A O L$}

Figure 5B shows the X-ray diffractograms of AOL, Evonik P25 and anatase. Evonik P25 $\left(80 \%\right.$ anatase/20\% rutile) exhibits some characteristic peaks at $2 \theta$ values of $25.37^{\circ}, 37.86^{\circ}$ and $48.12^{\circ}$ corresponding to (101), (004) and (200) lattice planes in anatase and at $27.52^{\circ}$ and $36.18^{\circ}$ associated to (110) and (101) plane in rutile [31,32]. In the case of AOL only anatase reflections are observed at $2 \theta$ values of $25.64^{\circ}, 38.21^{\circ}, 48.14^{\circ}, 54.75^{\circ}, 63.30^{\circ}, 69.54^{\circ}$ and $75.48^{\circ}$ assigned, respectively, to (101), (004), (211), (204), (116) (220) and (215) reflections [32].

It has been reported that pure $\mathrm{TiO}_{2}$ calcined at $500{ }^{\circ} \mathrm{C}$ exhibits the crystalline anatase phase [33] while the rutile phase begins to develop upon calcination at temperatures from $550{ }^{\circ} \mathrm{C}$. Nevertheless, the presence of additives retards the crystallization of the anatase phase and its transformation into rutile [34]. In our case, the presence of trace elements from the olive leaf (evidenced by XRF) could act in this direction and, therefore, for the AOL material calcined at $550{ }^{\circ} \mathrm{C}$, wide peaks corresponding to the anatase phase are observed, probably associated with a delayed crystallization of the material.

Average crystallite sizes of $\mathrm{TiO}_{2}$ were determined applying the Scherrer formula using the (101) and (110) diffraction peaks for anatase and rutile, respectively. Therefore, anatase crystallite sizes of 7.5, 20 and $21 \mathrm{~nm}$ were found for AOL, anatase and P25, respectively. Rutile crystallite size in P25 is $39 \mathrm{~nm}$. Crystallite sizes for P25 are consistent with those reported in the literature [30]. 
Identification of crystalline phases of $\mathrm{TiO}_{2}$ in samples was also performed by Raman spectroscopy, which is more sensitive than XRD [34] (Figure 5C). AOL exhibited three bands at 399.8, 520.8 and $640.6 \mathrm{~cm}^{-1}$ attributed to active modes of anatase with the symmetries B1g, A1g and Eg, respectively [32,35], while no bands associated to rutile phase were detected. Moreover, unlike XRD, Raman allowed us to identify some very small brookite signals at 245.9 and $328.1 \mathrm{~cm}^{-1}$ (A1g and B1g, respectively) [36]. In the case of Evonik P25, Raman spectroscopy confirmed the additional presence of rutile, with a characteristic signal at $446.8 \mathrm{~cm}^{-1}$ (Eg symmetry) [37].

Morphological and structural characterization indicates that the micro and nano structure of the olive oil has been successfully replicated and that the obtained solid has a granular morphology consisting of small crystallites of anatase $(7.5 \mathrm{~nm})$, and brookite to a lesser extent, with channels interconnecting internal structures, leading to a high surface area solid.

The solids were also analyzed by XPS. Ti2p3/2 signal (Figure 6A) can be deconvolved in two peaks at ca. $458.5 \mathrm{eV}$ and $457.0 \mathrm{eV}$ which are associated to $\mathrm{Ti}^{4+}$ and $\mathrm{Ti}^{3+}$, respectively [38-41]. The latter signal represents $1.9 \%, 4.3 \%$ and $6.5 \%$ of titanium signal in anatase, P25 and AOL, respectively. O1s spectra of the samples (Figure 6B) exhibit three signals centered at 529.8, 531.3 and 532.6 eV which are assigned in the literature to lattice oxygen atoms, surface hydroxyl groups and chemisorbed $\mathrm{O}_{2}$, respectively. The peak at ca. $532.6 \mathrm{eV}$ is associated to the existence of surface defects (such as oxygen vacancies) for $\mathrm{O}_{2}$ absorption [42]. It represents $4.3 \%, 5.4 \%$ and $7.2 \%$ of oxygen signal in anatase, P25 and AOL, respectively. XPS confirmed the presence of nitrogen in AOL (0.96 wt \%). Furthermore, N1s signal is centered at $400 \mathrm{eV}$ (Figure 6C) which is associated to interstitial N-doping [43].

UV-Vis spectra of the solids are presented in Figure 6D. As can be seen, absorption of AOL is shifted to the visible range as compared to P25 and anatase. Therefore, band gaps of 2.98, 3.12 and $3.22 \mathrm{eV}$, respectively, were found (see inset in Figure 6D). The absorption of visible light by AOL could be the result of a synergistic effect of defects (such as oxygen vacancies) and nitrogen species $[44,45]$ which were found to a larger extent in AOL than in anatase and P25. Oxygen vacancies can give rise to local states below the conduction band. Therefore, the excitation of electrons from the valence band to the oxygen vacancy level results in typical excitations in the visible range. Furthermore, electrons in the oxygen vacancies can interact with adjacent $\mathrm{Ti}^{4+}$ and lead to $\mathrm{Ti}^{3+}$ species which form a shallow donor level below the conduction band thus also contributing to the visible light response. XPS confirmed that $\mathrm{Ti}^{3+}$ species were particularly abundant in AOL. Moreover, oxygen vacancies are stabilized by doping nitrogen. $\mathrm{N}$ doping at levels up to $1 \%$ can also lead to visible light response because of the $\mathrm{N}-2 \mathrm{p}$ narrow band above the O-2p valence band [46]. The contribution of some other dopant elements which were already present in the olive leaves (e.g., P, C) $[47,48]$ to the redshift of light absorption in AOL cannot be ruled out.

Finally, some complementary electron paramagnetic resonance (EPR) experiments were carried out. Results are summarized in Figure 7. EPR signals at $\mathrm{g}<2$ are typically associated to electron trapping sites, such as $\mathrm{Ti}^{3+}$, whereas those with $\mathrm{g}>2$ are ascribed to hole trapping sites such as oxygen radical anion species $\mathrm{O}^{\bullet-}$ [46]. EPR spectrum of AOL without illumination presented signals at $\mathrm{g}=1.983,2.004$ and 2.019 which can be attributed to $\mathrm{Ti}^{3+}$, single ionized oxygen vacancy $\mathrm{F}^{+}$centers (also referred to as colored centers) and $\mathrm{O}^{\bullet-}$ species (resulting from reaction of $\mathrm{Ti}^{3+}$ with adsorbed oxygen), respectively [49]. In the case of P25 electron trapping sites are slightly shifted to lower $g$ values ( $g=1.981$ ) which is indicative of the presence of rutile [46]. $\mathrm{N}$ atoms can also contribute to the signal at $\mathrm{g}=2.004$ as nitroxide radicals $\mathrm{NO} \bullet$ [50].

All in all, a comparison of EPR spectra without illumination of AOL and P25 suggests a higher presence of surface defects in AOL (more intense EPR signals), which is consistent with the larger amount of oxygen vacancies and $\mathrm{Ti}^{+3}$ species observed in XPS results and the redshift of light absorption observed for AOL.

Illumination of samples results in the excitation of electrons from the valence to the conduction band, thus leading to electron and hole trapping sites $\left(\mathrm{Ti}^{3+}\right.$ and e.g., $\mathrm{O}^{\bullet-}$ at $\mathrm{g}<2$ and $\mathrm{g}>2$, respectively). If signals obtained for catalysts under visible and UV irradiation in the region of $\mathrm{g}>2$ are compared, 
intensity and areas are higher for AOL than for P25. Moreover, the increase in signals from solar to UV irradiation is greater for AOL than for P25 (e.g., areas from 3250-3360 gauss multiplied for 3.5 and 2.8, respectively). This could suggest a lower electron-hole recombination in AOL, this difference being more relevant under UV irradiation.
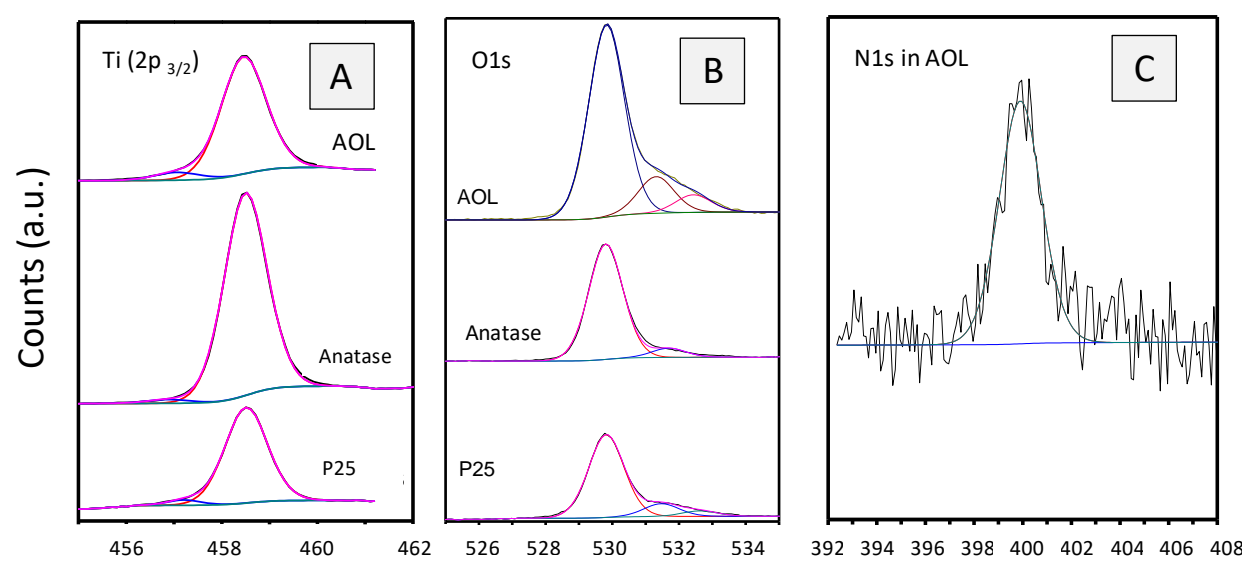

Binding Energy (eV)

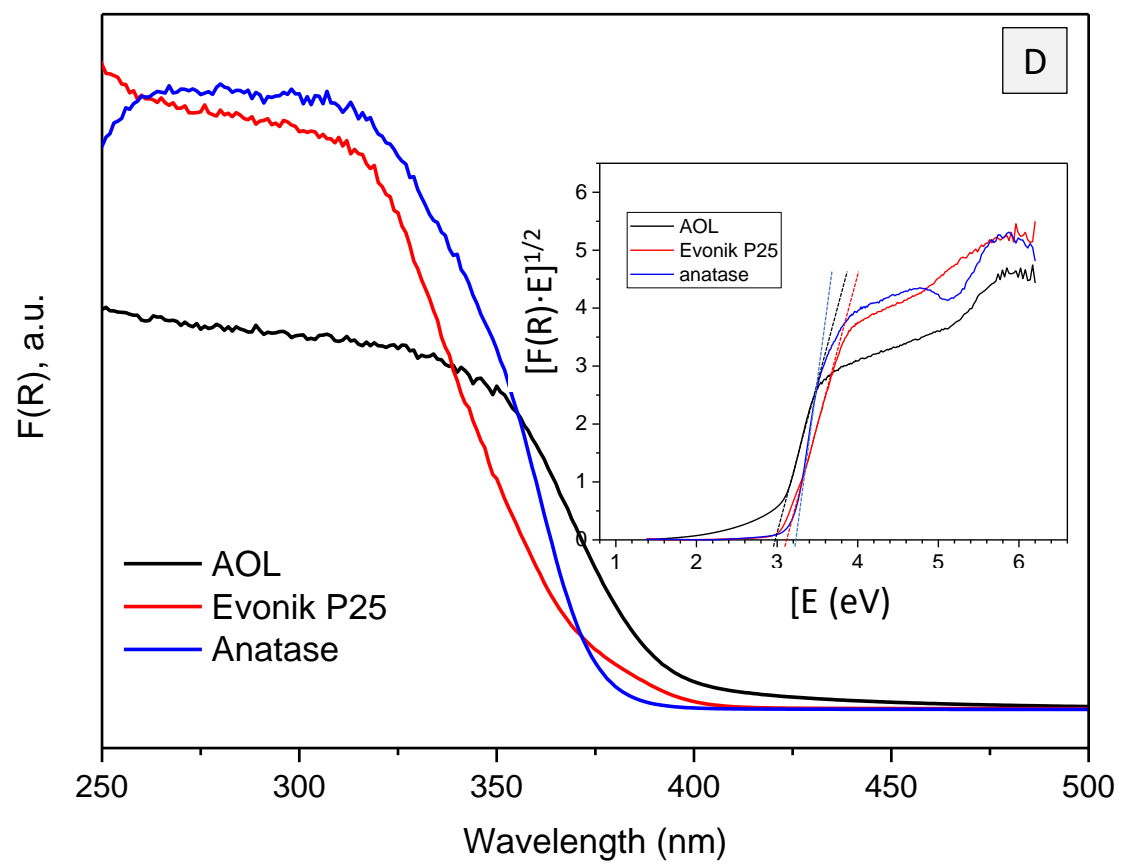

Figure 6. Characterization of AOL. X-ray photoelectron (XPS) profiles of Ti 2 $\mathrm{p}_{3 / 2}(\mathbf{A}), \mathrm{O} 1 \mathrm{~s}(\mathbf{B})$ and N $1 \mathrm{~s}$ (C). Titanium and oxygen profiles of anatase and Evonik P25 have also been included for comparison. (D) UV-Vis spectra of AOL, anatase and Evonik P25. The inset represents the plot of transformed Kubelka-Munk function vs. the energy of the absorbed light for determination of the band-gap energy. 


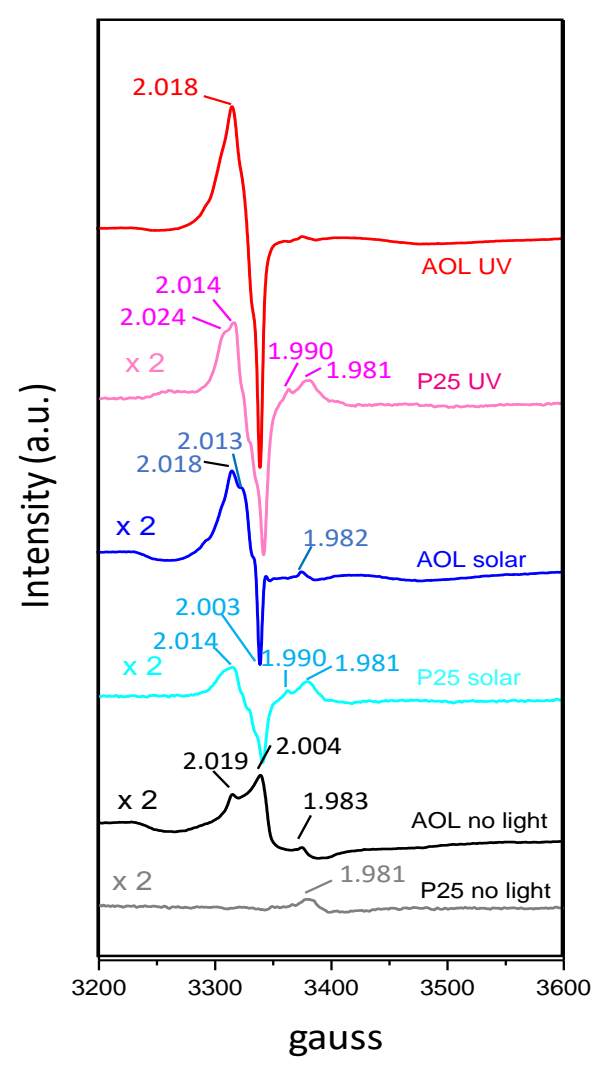

Figure 7. EPR spectra of Evonik P25 and AOL with (UV or solar) and without irradiation.

The solids were tested for hydrogen production through photocatalytic reforming of glycerol both under UV and solar light in the devices shown in Figure 2A,B. The preliminary results are summarized in Table 2.

As can be seen, both under UV and solar irradiation, hydrogen production followed the sequence: AOL > P25 > anatase. In fact, under solar light, AOL produced 64\% more hydrogen after $6 \mathrm{~h}$ than Evonik P25. Such an improvement was even higher under UV irradiation (143\%). These results suggest that AOL better catalytic performance cannot be only associated to the observed redshift in light adsorption (i.e., a larger amount of useful irradiation to activate the process which would be important under solar irradiation) but to the more effective use of existing radiation, as a result of the reduced electron-hole recombination under both solar and UV radiation. These would be in line with the above-commented higher increase of EPR bands at $g>2$ for AOL as compared to P25 when solar light is replaced by UV irradiation.

Table 2. Hydrogen photo-production on P25, AOL and anatase simples using UV or solar light.

\begin{tabular}{ccccc}
\hline \multirow{2}{*}{ Catalyst } & \multicolumn{4}{c}{ Hydrogen Production ( $\mu$ mol/gcat) } \\
& UV (3 h) & UV (6 h) & Solar (3 h) & Solar (6 h) \\
\hline P25 & 459.8 & 767.6 & 79.3 & 137.7 \\
AOL & 1035.2 & 1872.5 & 149.6 & 225.9 \\
Anatase & 372.8 & 669.9 & 52.4 & 73.3 \\
\hline
\end{tabular}

\section{Conclusions}

Olive leaves were used as templates to synthesize a titania-based solid (artificial olive leaf, AOL). AOL structure successfully replicated that of olive leaves (as evidenced by SEM) resulting in a $52 \mathrm{~m}^{2} \cdot \mathrm{g}^{-1}$ material with macro, meso and microporous (nitrogen-isotherms). The solid is mainly constituted by titania in the anatase form (XRD and Raman) and showed a redshift in light adsorption as compared to 
reference anatase and P25 titania (as evidenced by UV-Vis). The solid also contains some other minor elements present in olive leaves such as nitrogen $(1 \%)$ or carbon $(1.6 \%)$. AOL was preliminarily tested as a catalyst for hydrogen production through glycerol photoreforming. The activity of AOL was $64 \%$ and $144 \%$ higher than that of Evonik P25 reference material under solar or UV irradiation. Both the redshift in light absorption and the reduction in electron-hole recombination (as suggested by EPR) could account for that. All in all, this manuscript widens the scope of potential applications of olive leaves, a major bioproduct in Andalusia, as a biotemplate for the synthesis of photocatalysts.

Author Contributions: Funding acquisition, F.J.U. and A.M.; Conceptualization, F.J.U., A.M. and J.H.-C.; Methodology, A.M. and J.H.-C.; Investigation, J.H.-C., J.M.-G., M.C.H.-B. Analysis, J.H.-C., J.M.-G., M.C.H.-B. and R.C.E. Writing-Original draft preparation, J.H.-C., J.M.-G. and R.C.E.; Writing-Review and editing, A.M., F.J.U., J.H.-C.; Supervision, F.J.U. and A.M. Projects administration, F.J.U. and A.M. All authors have read and agreed to the published version of the manuscript.

Funding: This research was funded by the Spanish Ministerio de Economia y Competitividad, grant number ENE2016-81013-R (AEI/FEDER, EU) and Andalusian Government (UCO-FEDER Project CATOLIVAL, ref. 1264113-R, 2018 call).

Acknowledgments: A. Vidal and T. Blasco are gratefully acknowledged for their help in setting-up the EPR experimental device. The authors also wish to thank the staff at the central service for analysis (SCAI) at the University of Córdoba for the kind technical assistance in XPS, SEM, Raman and CHN elemental analysis experiments.

Conflicts of Interest: The authors declare no conflict of interest. The funders had no role in the design of the study; in the collection, analyses, or interpretation of data; in the writing of the manuscript, or in the decision to publish the results.

\section{References}

1. Sanchez, C.; Arribart, H.; Giraud Guille, M.M. Biomimetism and bioinspiration as tools for the design of innovative materials and systems. Nat. Mater. 2005, 4, 277-288. [CrossRef] [PubMed]

2. Hashemizadeh, I. Novel $\mathrm{CO}_{2}$ Capture and Conversion into Fuels via Artificial Photosynthesis by Artificial Inorganic Leaves, 2017. Ph.D. Thesis, University of Canterbury, Canterbury, New Zealand, 2017.

3. Xia, F.; Jiang, L. Bio-Inspired, Smart, Multiscale Interfacial Materials. Adv. Mater. 2008, 20, $2842-2858$. [CrossRef]

4. Lu, A.H.; Schüth, F. Nanocasting: A versatile strategy for creating nanostructured porous materials. Adv. Mater. 2006, 18, 1793-1805. [CrossRef]

5. Zhou, H.; Fan, T.; Zhang, D. Biotemplated materials for sustainable energy and environment: Current status and challenges. ChemSusChem 2011, 4, 1344-1387. [CrossRef]

6. Cheng, C.; Karuturi, S.K.; Liu, L.; Liu, J.; Li, H.; Su, L.T.; Tok, A.I.Y.; Fan, H.J. Quantum-dot-sensitized $\mathrm{TiO}_{2}$ inverse opals for photoelectrochemical hydrogen generation. Small 2012, 8, 37-42. [CrossRef]

7. Waterhouse, G.I.N.; Waterland, M.R. Opal and inverse opal photonic crystals: Fabrication and characterization. Polyhedron 2007, 26, 356-368. [CrossRef]

8. Li, X.H.; Liu, W.M.; Li, H.L. Template synthesis of well-aligned titanium dioxide nanotubes. Appl. Phys. A 2005, 80, 317-320. [CrossRef]

9. Nikolaidis, P.; Poullikkas, A. A comparative overview of hydrogen production processes. Renew. Sustain. Energy Rev. 2017, 67, 597-611. [CrossRef]

10. López-Tenllado, F.J.; Hidalgo-Carrillo, J.; Montes, V.; Marinas, A.; Urbano, F.J.; Marinas, J.M.; Ilieva, L.; Tabakova, T.; Reid, F. A comparative study of hydrogen photocatalytic production from glycerol and propan-2-ol on $\mathrm{M} / \mathrm{TiO}_{2}$ systems ( $\left.\mathrm{M}=\mathrm{Au}, \mathrm{Pt}, \mathrm{Pd}\right)$. Catal. Today 2017, 280, 58-64. [CrossRef]

11. Barreca, D.; Carraro, G.; Gombac, V.; Gasparotto, A.; Maccato, C.; Fornasiero, P.; Tondello, E. Supported metal oxide nanosystems for hydrogen photogeneration: Quo vadis? Adv. Funct. Mater. 2011, 21, 2611-2623. [CrossRef]

12. Woan, K.; Pyrgiotakis, G.; Sigmund, W. Photocatalytic carbon-nanotube-TiO 2 composites. Adv. Mater. 2009, 21, 2233-2239. [CrossRef]

13. López-Tenllado, F.J.; Hidalgo-Carrillo, J.; Montes-Jiménez, V.; Sánchez-López, E.; Urbano, F.J.; Marinas, A. Photocatalytic production of hydrogen from binary mixtures of $\mathrm{C}-3$ alcohols on $\mathrm{Pt} / \mathrm{TiO}_{2}$ : Influence of alcohol structure. Catal. Today 2019, 328, 2-7. [CrossRef] 
14. Kapridaki, C.; Xynidis, N.; Vazgiouraki, E.; Kallithrakas-Kontos, N.; Maravelaki-Kalaitzaki, P. Characterization of Photoactive $\mathrm{Fe}-\mathrm{TiO}_{2}$ Lime Coatings for Building Protection: The Role of Iron Content. Materials 2019, 12, 1847. [CrossRef] [PubMed]

15. Clarizia, L.; Vitiello, G.; Pallotti, D.K.; Silvestri, B.; Nadagouda, M.; Lettieri, S.; Luciani, G.; Andreozzi, R.; Maddalena, P.; Marotta, R. Effect of surface properties of copper-modified commercial titanium dioxide photocatalysts on hydrogen production through photoreforming of alcohols. Int. J. Hydrogen Energy 2017, 42, 28349-28362. [CrossRef]

16. Hidalgo-Carrillo, J.; Martín-Gómez, J.; Morales, J.; Espejo, J.C.; Urbano, F.J.; Marinas, A. Hydrogen Photo-Production from Glycerol Using Nickel-Doped $\mathrm{TiO}_{2}$ Catalysts: Effect of Catalyst Pre-Treatment. Energies 2019, 12, 3351. [CrossRef]

17. Štengl, V.; Bakardjieva, S.; Grygar, T.M.; Bludská, J.; Kormunda, M. $\mathrm{TiO}_{2}$-graphene oxide nanocomposite as advanced photocatalytic materials. Chem. Cent. J. 2013, 7, 41. [CrossRef] [PubMed]

18. Wang, Y.; Zu, M.; Zhou, X.; Lin, H.; Peng, F.; Zhang, S. Designing efficient $\mathrm{TiO}_{2}$-based photoelectrocatalysis systems for chemical engineering and sensing. Chem. Eng. J. 2020, 381, 122605. [CrossRef]

19. Li, X.; Fan, T.; Zhou, H.; Chow, S.-K.; Zhang, W.; Zhang, D.; Guo, Q.; Ogawa, H. Enhanced Light-Harvesting and Photocatalytic Properties in Morph-TiO 2 from Green-Leaf Biotemplates. Adv. Funct. Mater. 2009, 19, 45-56. [CrossRef]

20. Chen, A.; Qian, J.; Chen, Y.; Lu, X.; Wang, F.; Tang, Z. Enhanced sunlight photocatalytic activity of porous $\mathrm{TiO}_{2}$ hierarchical nanosheets derived from petal template. Powder Technol. 2013, 249, 71-76. [CrossRef]

21. Mohamed, M.A.; Salleh, W.N.W.; Jaafar, J.; Mohd Hir, Z.A.; Rosmi, M.S.; Mutalib, M.A.; Ismail, A.F.; Tanemura, M. Regenerated cellulose membrane as bio-template for in-situ growth of visible-light driven C-modified mesoporous titania. Carbohydr. Polym. 2016, 146, 166-173. [CrossRef]

22. Hashemizadeh, I.; Golovko, V.B.; Choi, J.; Tsang, D.C.W.; Yip, A.C.K. Photocatalytic reduction of $\mathrm{CO}_{2}$ to hydrocarbons using bio-templated porous $\mathrm{TiO}_{2}$ architectures under $\mathrm{UV}$ and visible light. Chem. Eng. J. 2018, 347, 64-73. [CrossRef]

23. La Biomasa en Andalucía. Available online: https:/www.agenciaandaluzadelaenergia.es/sites/default/files/ documentos/la_biomasa_en_andalucia_diciembre_2017.pdf (accessed on 29 May 2020).

24. Procopio, A.; Alcaro, S.; Nardi, M.; Oliverio, M.; Ortuso, F.; Sacchetta, P.; Pieragostino, D.; Sindona, G. Synthesis, biological evaluation, and molecular modeling of oleuropein and its semisynthetic derivatives as cyclooxygenase inhibitors. J. Agric. Food Chem. 2009, 57, 11161-11167. [CrossRef] [PubMed]

25. Nardi, M.; Bonacci, S.; Cariati, L.; Costanzo, P.; Oliverio, M.; Sindona, G.; Procopio, A. Synthesis and antioxidant evaluation of lipophilic oleuropein aglycone derivatives. Food Funct. 2017, 8, 4684-4692. [CrossRef] [PubMed]

26. Hashemizadeh, I.; Tsang, D.C.W.; Ng, Y.H.; Wu, Z.; Golovko, V.; Yip, A.C.K. Bio-mimicking TiO 2 architectures for enhanced photocatalytic activity under UV and visible light. RSC Adv. 2017, 7, 39098-39108. [CrossRef]

27. Alcázar-Román, R.; Amorós, J.A.; Pérez de los Reyes, C.; García-Navarro, F.J.; Bravo, S. Major and trace element content of olive leaves. Olivæ 2014, 119, 1-7. [CrossRef]

28. García-Gómez, A.; Roig, A.; Bernal, M. Composting of the solid fraction of olive mill wastewater with olive leaves: Organic matter degradation and biological activity. Bioresour. Technol. 2003, 86, 59-64. [CrossRef]

29. Bakardjieva, S.; Šubrt, J.; Štengl, V.; Dianez, M.J.; Sayagues, M.J. Photoactivity of anatase-rutile $\mathrm{TiO}_{2}$ nanocrystalline mixtures obtained by heat treatment of homogeneously precipitated anatase. Appl. Catal. B Environ. 2005, 58, 193-202. [CrossRef]

30. Abu Bakar, N.I.; Chandren, S.; Attan, N.; Leaw, W.L.; Nur, H. One-dimensional-like titania/4'-pentyl-4-biphenylcarbonitrile composite synthesized under magnetic field and its structure-photocatalytic activity relationship. Front. Chem. 2018, 6, 370. [CrossRef]

31. Wang, Y.; Li, L.; Huang, X.; Li, Q.; Li, G. New insights into fluorinated $\mathrm{TiO}_{2}$ (brookite, anatase and rutile) nanoparticles as efficient photocatalytic redox catalysts. RSC Adv. 2015, 5, 34302-34313. [CrossRef]

32. Verma, R.; Gangwar, J.; Srivastava, A.K. Multiphase $\mathrm{TiO}_{2}$ nanostructures: A review of efficient synthesis, growth mechanism, probing capabilities, and applications in bio-safety and health. RSC Adv. 2017, 7, 44199-44224. [CrossRef] 
33. El-Sheikh, S.M.; Zhang, G.; El-Hosainy, H.M.; Ismail, A.A.; O'Shea, K.E.; Falaras, P.; Kontos, A.G.; Dionysiou, D.D. High performance sulfur, nitrogen and carbon doped mesoporous anatase-brookite $\mathrm{TiO}_{2}$ photocatalyst for the removal of microcystin-LR under visible light irradiation. J. Hazard. Mater. 2014, 280, 723-733. [CrossRef] [PubMed]

34. Zhang, J.; Li, M.; Feng, Z.; Chen, J.; Li, C. UV raman spectroscopic study on $\mathrm{TiO}_{2}$ - I. phase transformation at the surface and in the bulk. J. Phys. Chem. B 2006, 110, 927-935. [CrossRef] [PubMed]

35. Miao, L.; Tanemura, S.; Toh, S.; Kaneko, K.; Tanemura, M. Fabrication, characterization and Raman study of anatase- $\mathrm{TiO}_{2}$ nanorods by a heating-sol-gel template process. J. Cryst. Growth 2004, 264, 246-252. [CrossRef]

36. Iliev, M.N.; Hadjiev, V.G.; Litvinchuk, A.P. Raman and infrared spectra of brookite $\left(\mathrm{TiO}_{2}\right)$ : Experiment and theory. Vib. Spectrosc. 2013, 64, 148-152. [CrossRef]

37. Tuschel, D. Raman Spectroscopy and Polymorphism. Spectroscopy 2019, 34, 10-21.

38. Wang, N.; Lin, H.; Li, J.B.; Yang, X.Z.; Chi, B. Synthesis of Titanium Dioxide Nanotubes by Ion Exchange Approach. Mater. Sci. Forum 2005, 475-479, 1235-1238. [CrossRef]

39. Temperton, R.H.; Gibson, A.; O'Shea, J.N. In situ XPS analysis of the atomic layer deposition of aluminium oxide on titanium dioxide. Phys. Chem. Chem. Phys. 2019, 21, 1393-1398. [CrossRef]

40. Rugen, E.E.; Koczkur, K.M.; Skrabalak, S.E. Facile synthesis of porous $\mathrm{La}-\mathrm{Ti}-\mathrm{O}$ and $\mathrm{LaTiO}_{2} \mathrm{~N}$ microspheres. Dalt. Trans. 2017, 46, 10727-10733. [CrossRef]

41. Pennington, A.M.; Yang, R.A.; Munoz, D.T.; Celik, F.E. Metal-free hydrogen evolution over defect-rich anatase titanium dioxide. Int. J. Hydrogen Energy 2018, 43, 15176-15190. [CrossRef]

42. Zhang, Z.; Long, J.; Xie, X.; Zhuang, H.; Zhou, Y.; Lin, H.; Yuan, R.; Dai, W.; Ding, Z.; Wang, X.; et al. Controlling the synergistic effect of oxygen vacancies and $\mathrm{N}$ dopants to enhance photocatalytic activity of $\mathrm{N}$-doped $\mathrm{TiO}_{2}$ by $\mathrm{H}_{2}$ reduction. Appl. Catal. A Gen. 2012, 425-426, 117-124. [CrossRef]

43. Di Valentin, C.; Pacchioni, G.; Selloni, A.; Livraghi, S.; Giamello, E. Characterization of paramagnetic species in $\mathrm{N}$-doped $\mathrm{TiO}_{2}$ powders by EPR spectroscopy and DFT calculations. J. Phys. Chem. B 2005, 109, 11414-11419. [CrossRef] [PubMed]

44. Miyauchi, M.; Ikezawa, A.; Tobimatsu, H.; Irie, H.; Hashimoto, K. Zeta potential and photocatalytic activity of nitrogen doped $\mathrm{TiO}_{2}$ thin films. Phys. Chem. Chem. Phys. 2004, 865-870. [CrossRef]

45. Pan, X.; Yang, M.Q.; Fu, X.; Zhang, N.; Xu, Y.J. Defective $\mathrm{TiO}_{2}$ with oxygen vacancies: Synthesis, properties and photocatalytic applications. Nanoscale 2013, 5, 3601-3614. [CrossRef] [PubMed]

46. Muñoz-Batista, M.J.; Ballari, M.M.; Kubacka, A.; Alfano, O.M.; Fernández-García, M. Braiding kinetics and spectroscopy in photo-catalysis: The spectro-kinetic approach. Chem. Soc. Rev. 2019, 48, 637-682. [CrossRef] [PubMed]

47. Asapu, R.; Palla, V.M.; Wang, B.; Guo, Z.; Sadu, R.; Chen, D.H. Phosphorus-doped titania nanotubes with enhanced photocatalytic activity. J. Photochem. Photobiol. A Chem. 2011, 225, 81-87. [CrossRef]

48. Palanivelu, K.; Im, J.-S.; Lee, Y.-S. Carbon Doping of $\mathrm{TiO}_{2}$ for Visible Light Photo Catalysis-A review. Carbon Lett. 2007, 8, 214-224. [CrossRef]

49. Santara, B.; Giri, P.K.; Imakita, K.; Fujii, M. Evidence for Ti interstitial induced extended visible absorption and near infrared photoluminescence from undoped $\mathrm{TiO}_{2}$ nanoribbons: An in situ photoluminescence study. J. Phys. Chem. C 2013, 117, 23402-23411. [CrossRef]

50. Melhem, H.; Simon, P.; Wang, J.; Di Bin, C.; Ratier, B.; Leconte, Y.; Herlin-Boime, N.; Makowska-Janusik, M.; Kassiba, A.; Bouclé, J. Direct photocurrent generation from nitrogen doped $\mathrm{TiO}_{2}$ electrodes in solid-state dye-sensitized solar cells: Towards optically-active metal oxides for photovoltaic applications. Sol. Energy Mater. Sol. Cells 2013, 117, 624-631. [CrossRef]

(C) 2020 by the authors. Licensee MDPI, Basel, Switzerland. This article is an open access article distributed under the terms and conditions of the Creative Commons Attribution (CC BY) license (http://creativecommons.org/licenses/by/4.0/). 